\title{
Simulations of an isolated two-dimensional thunderstorm: sensitivity to cloud droplet size and the presence of graupel
}

Mary-Jane Morongwa Bopape ${ }^{1,2}$, Francois Alwyn Engelbrecht ${ }^{1,3}$, David A Randall ${ }^{4}$ and

\author{
Willem Adolf Landman ${ }^{1,2}$ \\ ${ }^{1}$ Natural Resources and the Environment, Council for Scientific and Industrial Research, Pretoria, \\ South Africa \\ ${ }^{2}$ Department of Geography, Geoinformatics and Meteorology, University of Pretoria, Pretoria, South \\ Africa \\ ${ }^{3}$ Department of Geography, Archeology and Environmental Sciences, University of the \\ Witwatersrand, Johannesburg, South Africa \\ ${ }^{4}$ Department of Atmospheric Science, Colorado State University, Fort Collins, Colorado, United States
}

Corresponding Author: Mary-Jane Bopape, Council for Scientific and Industrial Research, Building 33, P O Box 395, Pretoria, 0001

E-mail : mbopape@csir.co.za

\begin{abstract}
Cloud Resolving Models (CRMs) which are used increasingly to make operational forecasts, employ Bulk Microphysics Schemes (BMSs) to describe cloud microphysical processes. In this study two BMSs are employed in a new Nonhydrostatic $\sigma$-coordinate Model to perform two hour simulations of convection initiated by a warm bubble, using a horizontal grid resolution of $500 \mathrm{~m}$. Different configurations of the two BMSs are applied, to test the effects of the presence of graupel with one scheme (2-configurations) and of changing the cloud droplet sizes in the second scheme (4-configurations), on the simulation of idealised thunderstorms. Maximum updrafts in all the simulations are similar over the first 40 minutes,
\end{abstract}


but start to differ beyond this point. The first scheme simulates the development of a second convective cell that is triggered by the cold pool that develops from the outflow of the first storm. The cold pool is more intense in the simulation with graupel because of melting of graupel particles, which results in relatively large raindrops, decreases the temperature trough latent heat absorption, causing stronger downdrafts, which all contribute to the formation of a more intense cold pool. The second scheme simulates the development of a second cell in two of its configurations, while two other configurations do not simulate the redevelopment. Two configurations that simulate the secondary redevelopment produce a slightly stronger cold pool just before redevelopment. Our results show that small differences in the microphysics formulations result in simulations of storm dynamics that diverge, possibly due nonlinearities in the model.

Key words: atmospheric modelling, cloud resolving model, microphysics schemes, thunderstorm, cold pool

\section{Introduction}

The parameterization of convective rainfall in atmospheric models is thought to be a major source of uncertainty in model projections of future climate change (Arakawa, 2004; Palmer, 2012). These models are currently applied at hydrostatic resolutions where the dynamics of the individual storms systems are not explicitly resolved. It is thought that the application of climate models beyond the hydrostatic limit, where the dynamics of convective storms are at least partially resolved, may reduce this uncertainty (Randall et al., 2003; Liu and Moncrief, 2007). Although present-day computational power does not allow extended simulations of climate at nonhydrostatic resolutions, the resolution of short-range Numerical Weather Prediction (NWP) models over limited areas has reached this threshold (e.g. Davies et al., 2003; Harper et al., 2007). In fact, many centers have in recent years developed 
nonhydrostatic versions of existing hydrostatic models (Xue et al., 2000, Davies et al., 2005; Satoh et al., 2005; Abiodun et al., 2008). Moreover, some climate models employ superparameterization schemes, which rely on the explicit simulation of storm dynamics in two spatial dimensions, at resolutions beyond the hydrostatic limit (Grabowski, 2000, Randall et al., 2003; Khairoutdinov et al., 2004). It is therefore meaningful to investigate the sensitivity of explicit simulations of convective rainfall and storm dynamics to the microphysical parameterizations applied at these high spatial resolutions, as these schemes are a potential source of uncertainty, or possibly a means to describe the uncertainty envelope, in simulations beyond the hydrostatic limit.

Nonhydrostatic models that include the necessary physics to simulate ensembles of clouds explicitly over a large enough domain are called Cloud Resolving Models (CRMs) or Cumulus Ensemble Models (Randall et al., 1996). Such a model is applied in this research to study the sensitivity of simulated storm dynamics and convective rainfall to different microphysical parameterizations. This model uses a pressure-based $\sigma$-coordinate (Phillips, 1956) in the vertical and is called the Nonhydrostatic $\sigma$-coordinate Model (NSM) (Engelbrecht et al., 2007). The model is the $\sigma$-coordinate equivalent of White (1989)'s pressure coordinate model, which in turns differs from the earlier derived Miller-Pearce model ( Miller, 1974; Miller and Pearce, 1974; Miller and White, 1984) in the sense that it does not make use of a reference thermodynamic state.

The majority of CRMs use Bulk Microphysics Schemes (BMSs) to simulate clouds explicitly (Kessler, 1969; Rutledge and Hobbs, 1983; Stensrud 2007), because BMSs are computationally economic compared to the bin approach which calculates the hydrometeor distributions explicitly (Stensrud, 2007; Straka, 2009). BMSs specify a functional form for the particle distribution and usually predict the mixing ratios of as few as possible water substance classes (Straka and Mansel, 2005; Rutledge and Hobbs, 1984; Lin et al., 1983; 
Stensrud, 2007; Van Weverberg et al., 2011). In a BMS the various cloud microphysics processes responsible for transferring the water substance from one species to another are parameterized. Double moment schemes predict both the particle mixing ratio and the concentration, while a single-moment scheme predicts only the particle mixing ratio (Wang and Chang, 1993; Morrison and Milbrandt, 2011; Morrison et al., 2009; Dawson et al., 2010). Tao et al. (2003) found that a single-moment scheme produced more and larger graupel in the convective towers and which were transported into the trailing portion of a squall system, while a double moment scheme produced smaller more abundant ice particles - the double moment scheme produced less rainfall.

A number of studies have been conducted that compared bulk schemes with different levels of complexity (i.e simple ice scheme to mixed phase schemes that predict the number concentration of at least one hydrometeor type) (e.g. Liu and Moncrief, 2007; Grubišić et al., 2005; Colle and Mass, 2000). These studies found that, in general the mixed-phase schemes outperformed the simple ice scheme in terms of total rainfall distribution and rainfall coherency but a general conclusion about the degree of sophistication in the microphysics treatment and the performance could not be reached. Colle and Mass (2000) included a warm-rain scheme in their comparison study and found that it performed worse than schemes that included ice. This finding suggests that single-moment schemes that include ice still have a role to play, even though the more complex and computationally expensive multi-moment bulk and bin schemes have received a lot of attention lately.

Hong and Lim (2006) compared a five and six class schemes and found that the amount of rainfall increased and its peak intensity became stronger with more hydrometeors. Van den Heever and Cotton (2004) showed that smaller hail produced stronger cold pools than large hail and that the supercell storm simulated with large hail dissipated later than the one with small hail. Gilmore et al. (2004) tested the effect of changing the hail distribution 
size by increasing the hail distribution intercept. The smaller hail resulted in larger upward fluxes of hail and smaller downward fluxes of hail and less precipitation at the surface. An increase in concentration of aerosols has been shown to increase the concentration and size of cloud droplets and reduce precipitation efficiency using multi-moment bulk and bin schemes (e.g. Khain et al., 2005; Khain and Lynn, 2009; Ćurić et al. 2007). Downdrafts were found to be stronger in clouds with more aerosols, and the downdrafts lead to the formation of a cold pool which fosters the formation of secondary clouds. In small aerosol concentration conditions, the secondary clouds were usually weak and did not reach the upper levels, while secondary clouds in more aerosol conditions were stronger.

Previous studies such as those mentioned above showed that there is an interplay between the dynamics and microphysics of thunderstorms which are highly dependent on the characteristics of the simulated hydrometeors and their distribution. Single-moment schemes which are used in NWP assume that the intercept of the hydrometeor distributions are constant, and these are thought to vary depending on the aerosol concentrations. It is therefore of interest to investigate the effect of keeping the intercept constant. In this study we use two microphysics schemes with different configurations to study the interplay of an individual thunderstorm dynamics and microphysics. An individual thunderstorm is of interest because it is the most common type of thunderstorm, and it is a building block of an ensemble of clouds that are usually simulated by CRMs ( Randall et al., 1996). An understanding of the source of differences in an individual thunderstorm simulation can help us understand differences in the simulations of an ensemble of clouds. Xu et al. (2000) compared two-dimensional (2-D) and three-dimensional (3-D) simulations of midlatitude continental convection and found that 2-D model produce similar statistical properties of cumulus convection to the 3-D versions. They recommended the application of 2-D models for testing microphysics schemes because of their computational economy. In the next 
section the basic equations of the NSM are discussed and the experimental design of the numerical simulations performed is presented. The simulation results are subsequently discussed, followed by a summary and conclusions of the study.

\section{The Non-Hydrostatic $\sigma$-coordinate Model}

The first part of this section discusses the basic equations used in the NSM. The two microphysics schemes employed in the NSM are subsequently discussed. Finally, the experimental design of the numerical simulations is presented.

\section{a. The Governing Equations}

Engelbrecht (2006) and Engelbrecht et al. (2007) derived the NSM equation set as the $\sigma$-coordinate equivalent to the pressure coordinate equations of White (1989). The $\sigma$ coordinate is defined based on the full pressure field $p$, as

$$
\sigma=\frac{p-p_{T}}{p_{\text {surf }}-p_{T}}=\frac{p-p_{T}}{p_{s}}
$$

where $p_{T}$ is the prescribed pressure at the model top, $p_{\text {surf }}$ is the full surface pressure and $p_{s}=p_{\text {surf }}-p_{T}$. The sigma-coordinate equations are given by:

$$
\begin{aligned}
& \frac{D u}{D t}+\frac{\partial \varphi}{\partial x}-\sigma \frac{\partial \varphi}{\partial \sigma} \frac{\partial \ln \varphi}{\partial x}=0, \\
& \frac{R}{g} \frac{D}{D t}\left[\frac{\omega T}{p}\right]+g+\frac{p}{p_{s}} \frac{g}{R T} \frac{\partial \varphi}{\partial \sigma}=0, \\
& \frac{\partial u}{\partial x}+\frac{\partial \dot{\sigma}}{\partial \sigma}+\frac{D \ln p_{s}}{D t}=0, \\
& \frac{D T}{D t}-\frac{R T \omega}{c_{p} p}=S_{h}, \\
& \frac{D q_{x}}{D t}=S_{x}, \mathrm{x}=1, \ldots, \mathrm{n},
\end{aligned}
$$




$$
\frac{D q_{x}}{D t}=S_{x}+\frac{\partial}{\partial \sigma}\left(\rho V_{x} q_{x}\right) \frac{\partial \sigma}{\partial z}, \mathrm{x}=\mathrm{n}+1, \ldots, \mathrm{n}+\mathrm{k}
$$

In equations (2) to (7) the total derivative is given by

$$
\frac{D}{D t}=\frac{\partial}{\partial t}+u \frac{\partial}{\partial x}+\dot{\sigma} \frac{\partial}{\partial \sigma}
$$

where $\mathrm{x}$ represents the horizontal coordinate and $\mathrm{t}$ is time. All differentiations with respect to time and the horizontal coordinate are carried out at constant $\sigma$. The horizontal component of the wind is $\mathrm{u}, \varnothing$ is the geopotential height, $g z, z$ being geometric height; $\mathrm{T}$ is temperature, $\dot{\sigma}=D \sigma / D t$ and $\omega=D p / D t . R$ is the gas constant for dry air and $\kappa=R / c_{p}$, with $c_{p}$ the specific heat of dry air at constant pressure.

Equation 2 and 3 are the horizontal and vertical momentum equations, respectively. The continuity and thermodynamic equations are given by equations (4) and (5), respectively. The change in temperature due to microphysics processes is represented by the term on the right hand side of equation (5). Water continuity equations for all the non-falling and falling water classes in the model are given by equation 6 and equation 7, respectively. $q_{x}$ represents the different mixing ratios with $\mathrm{x}$ being the place holder for different species of the water substance. $S_{x}$ represents the microphysics processes that act as sources and sinks for $q_{x}$.

A variable $\Omega$ is defined based on the relation between the fields $\dot{\sigma}$ and $\omega$ as:

$$
\Omega=\frac{\omega}{p}=\frac{p_{s}}{\sigma p_{s}+p_{T}}\left(\sigma \frac{D \ln p_{s}}{D t}+\dot{\sigma}\right)
$$

following Miller and White (1984).

Equations (2) to (7) may be combined to obtain an elliptic equation (10) in the geopotential. An extra term appears in the elliptic equation as a result of the microphysics processes (compared to the dry adiabatic form of equation 10). No radiative forcing was applied in the simulations discussed in this study. 


$$
\begin{gathered}
\frac{\partial^{2} \varphi}{\partial x^{2}}+\frac{\partial}{\partial \sigma}\left[s^{2} \frac{\partial \varphi}{\partial \sigma}\right]-2 \sigma\left[\frac{\partial \ln p_{s}}{\partial x}\left(\frac{\partial^{2} \varphi}{\partial x \partial \sigma}\right)\right]+ \\
\frac{\partial}{\partial \sigma}\left(\sigma^{2} \frac{\partial \varphi}{\partial \sigma}\right)\left(\frac{\partial \ln p_{s}}{\partial x}\right)^{2}-\frac{\sigma}{p_{s}} \frac{\partial \varphi}{\partial \sigma}\left(\frac{\partial^{2} p_{s}}{\partial x^{2}}\right)= \\
2 \frac{\partial u}{\partial x} \frac{\partial}{\partial \sigma}\left(\frac{\Omega p}{p_{s}}\right)-\frac{2}{p_{s}} \frac{\partial u}{\partial \sigma} \frac{\partial}{\partial x}(p \Omega) \\
-\frac{\partial}{\partial \sigma}\left(s g-\frac{p}{p_{s}} \Omega^{2} \frac{1}{\gamma}\right)-\frac{\partial}{\partial \sigma}\left(\frac{S_{h} p \Omega}{p_{s} T}\right) .
\end{gathered}
$$

Here, $s=\left(\sigma+p_{T} / p_{s}\right)(g / R T)=(p / p s)(g / R T), \gamma=c_{p} / c_{v}$ and $S_{h}$ is heating or cooling due to latent heat release or absorption. Equation (10) is needed during the numerical solution of governing Equations (2) to (7). The turbulence scheme used in the model is a first-order local diffusion scheme that depends on the bulk Richardson number (Louis, 1979) and is modelled similar to Holtslag and Boville (1993).

\section{b. Cloud microphysics}

The two microphysics schemes used in the NSM were obtained from the National Centre for Atmospheric Research (NCAR) Weather Research and Forecasting (WRF) model (Skamarock et al., 2005). Single-moment schemes were chosen because they are cheaper to run, and therefore will be ideal in an operational environment or in extended, real-atmosphere simulations in three spatial dimensions. The first microphysics scheme that is chosen is thought to be a classic scheme (Lin et al., 1983; Rutledge and Hobbs, 1984, Chen and Sun, 2002) called PURDUE-LIN because it was developed at the Purdue University. It includes six classes of the water substance, namely water vapour, cloud water, cloud ice, rain, snow and graupel. It also uses the saturation adjustment of Tao et al. (1989). All precipitating fields 
are assumed to fall at their mass-weighted fall speed. Cloud water and cloud ice are assumed to be monodispersed and nonfalling. The scheme can be used both with five water classes (i.e. excluding graupel) and with six classes.

The second scheme is called SBU-YLIN (Lin and Colle, 2011) and was developed recently based on the PURDUE-LIN scheme, with the intention of improving the old scheme at the Stony Brook University (SBU). Although it is newer, the SBU-YLIN scheme was developed in a way that allows for a smaller number of microphysics processes to be calculated than in the PURDUE-LIN scheme, to make it computationally cheap. The SBUYLIN scheme includes five prognostic equations, for water vapour, cloud water, cloud ice, rain and precipitating ice. Dry snow, rimed snow and graupel are included in the precipitation ice category through the introduction of varying riming intensity parameters. The SBU-YLIN scheme uses a generalized gamma distribution to describe size distribution of cloud water droplets, $N_{c}=N_{0 c} D^{\mu} e^{-\lambda D}$ where $N_{0 \mathrm{C}}$ is the intercept, $\mu$ is the shape parameter, and $\lambda$ is the slope. The SBU-YLIN scheme is sensitive to $N_{0 \mathrm{C}}$ because it uses the Liu and Daum (2004) autoconversion. Rain and its related parameterizations are similar to the PURDUE-LIN scheme.

\section{c. Boundary conditions, numerical technique and initial conditions}

In this study we simulate the formation and development of an isolated thunderstorm within an environment with a thermodynamic profile described by Weisman and Klemp (1982). The initial profiles of the environmental potential temperature and relative humidity are given by:

$$
\theta(z)=\left\{\begin{array}{l}
\theta_{0}+\left(\theta_{t r}-\theta_{0}\right)\left(\frac{z}{z_{t r}}\right)^{(5 / 4)}, z \leq z_{t r} \\
\theta_{t r} \exp \left[\frac{g}{c_{p} T_{t r}}\left(z-z_{t r}\right)\right], z>z_{t r}
\end{array}\right.
$$




$$
H(z)=\left\{\begin{array}{l}
1-\frac{3}{4}\left(\frac{z}{z_{t r}}\right)^{(5 / 4)}, z \leq z_{t r} \\
0.25, z>z_{t r}
\end{array}\right.
$$

where $z_{\text {tr }}=12 \mathrm{~km}, \theta_{\mathrm{tr}}=343 \mathrm{~K}, T_{\text {tr }}=213 \mathrm{~K}$ and $\theta_{\mathrm{tr}}=300 \mathrm{~K}$. The mixing ratio of water vapour is kept constant at a maximum value of $q_{v 0}=0.014$ near the surface to represent a fairly well mixed boundary layer. The potential temperature is almost constant in this region. There is zero wind shear in the vertical.

To prevent upward-propagating disturbances from reflecting back into the domain when they encounter the upper boundary, a wave absorbing layer is placed over the upper part of the domain, from $17 \mathrm{~km}$ above sea-level upwards. Horizontal and vertical diffusion of the horizontal wind is applied in the sponge layer, with a vertically varying viscosity following Durran (1999). Without the application of the sponge layer, the model was found to become numerically unstable, due to the reflection of waves from the model top. Cyclic boundary conditions are applied at the lateral boundaries of the model.

Engelbrecht (2006) and Engelbrecht et al. (2007) developed a split semi-Lagragian method to solve the quasi-elastic $\sigma$-coordinate equations. That is, for numerical solution, the equations are split into an advective and nonadvective part. The slow advection process is treated during a semi-Langragian advection step that employs a large time step. Hereafter the remaining terms, which describe the fast moving waves, are treated explicitly during an adjustment phase that employs a smaller time step. The microphysics parameterisations are solved in the adjustment stage, while the diffusion scheme is applied after each advection step. The numerical scheme is formulated on a nonstaggered grid, to avoid the calculation of two sets of departure points for the semi-Lagrangian scheme. The Shapiro filter is applied to remove two-grid interval noise from the solution (see Engelbrecht, 2006). 


\section{d. Experimental Design}

The horizontal domain is $100 \mathrm{~km}$ wide and extends to about $25 \mathrm{~km}$ above sea level. The resolution of the model decreases gradually from the surface to the top. $125 \sigma$ levels are used, which provide an average resolution of about $200 \mathrm{~m}$ in the vertical. Simulations are made with the PURDUE-LIN scheme with graupel (PURDUE-LIN1) and without graupel (PURDUE-LIN2), and also with the SBU-YLIN microphysics scheme - with a horizontal resolution of $500 \mathrm{~m}$ used in all the simulations. Four simulations made with the SBU-YLIN scheme using $N_{0 \mathrm{C}}=10 \times 10^{6}$ (Nc10_SBU-YLIN),$N_{0 \mathrm{C}}=20 \times 10^{6}$ (Nc20_SBU-YLIN), $N_{\text {OC }}=40 \times 10^{6}\left(\mathrm{Nc} 40 \_\right.$SBU-YLIN) and $N_{0 \mathrm{C}}=60 \times 10^{6} \mathrm{~m}^{-4}\left(\mathrm{Nc} 60 \_\right.$SBU-YLIN) are studied. For the type of simulation made in this study, the developers of SBU-YLIN recommend the use of $N_{\text {OC }}=10$ or $20 \times 10^{6}$. Increasing the value of $N_{\mathrm{OC}}$ results in an increased number of smaller cloud droplets. Each $\mathrm{q}_{\mathrm{c}}$ distribution intersects the $\mathrm{y}$ axis at the value of the intercept parameters (Gilmore et al. 2004). At the beginning of the simulation, water vapour is provided and the hydrometeors are set to zero. The thunderstorm is triggered by a temperature perturbation of $2^{0} C$ which is specified at the center of the thermal, decreasing gradually to $0^{0} \mathrm{C}$ at its edge at the centre of the domain. The thermal has a radius of $10 \mathrm{~km}$. The NSM was subsequently integrated to perform simulations of two hours duration.

\section{Results}

In this section simulations made with the NSM employing two microphysics schemes, the PURDUE-LIN and SBU-YLIN schemes, are discussed. 


\section{a. Convective cells}

The PURDUE-LIN1 (Fig. 1a) and PURDUE-LIN2 (Fig. 1b) schemes simulate the formation of two convective cells, with the second smaller cell the result of redevelopment (Table 1). Note that in Fig 1, the contour lines represent the maximum updraft velocity

Table 1. Summary of results for an individual thunderstorm simulation showing the whether or not a second cell developed, the rank in the strength of the updrafts of the second cell, cold pool and downdrafts just before cell developed, and rank in terms of the domain averaged heating and converted water vapour by the end of the simulation made with PURDUE-LIN1 (P-D1), PURDUE-LIN2 (P-D2) and SBU-YLIN simulations with $\mathrm{Nc}=10$ (Nc10_S-Y), 20(Nc20_S-Y), 40 (Nc40_S-Y) and 60 (Nc60_S-Y).

\begin{tabular}{|c|c|c|c|c|c|c|}
\hline \multirow[t]{2}{*}{ Scheme } & \multirow[t]{2}{*}{$2^{\text {nd }}$ cell } & \multicolumn{5}{|c|}{ Rank of different aspects of the simulated thunderstorm } \\
\hline & & $\operatorname{Updraft}\left(2^{\text {nd }}\right)$ & downdraft & Cold pool & Lost qv & Heating \\
\hline P-L1 & Yes & 2 & 1 & 1 & 1 & 1 \\
\hline P-L2 & Yes & 1 & 2 & 2 & 2 & 2 \\
\hline Nc10_S-Y & No & $\mathrm{N} / \mathrm{A}$ & 5 & 5 & 5 & 5 \\
\hline Nc20_S-Y & Yes & 3 & 3 & 3 & 4 & 4 \\
\hline Nc40_S-Y & Yes & 4 & 4 & 4 & 3 & 3 \\
\hline Nc60_S-Y & No & $\mathrm{N} / \mathrm{A}$ & 5 & 5 & 5 & 5 \\
\hline
\end{tabular}

simulated by the scheme at a given height and a given point in time in minutes over a two hour period. The SBU-YLIN scheme (Fig. 1c) with the default value of $N_{0 \mathrm{C}}=10$ does not simulate the formation of the second cell. When the second recommended value by the scheme developers is used, i.e. $N_{0 \mathrm{C}}=20$ (Fig 1d), the SBU-YLIN scheme does simulate the redevelopment to occur. Nc40_SBU-YLIN (Fig 1e) also simulates a second cell, whilst Nc60_SBU-YLIN (Fig 1f) does not. The first cell is triggered by the thermal that is introduced at the beginning of the simulation. The maximum updrafts simulated are similar 

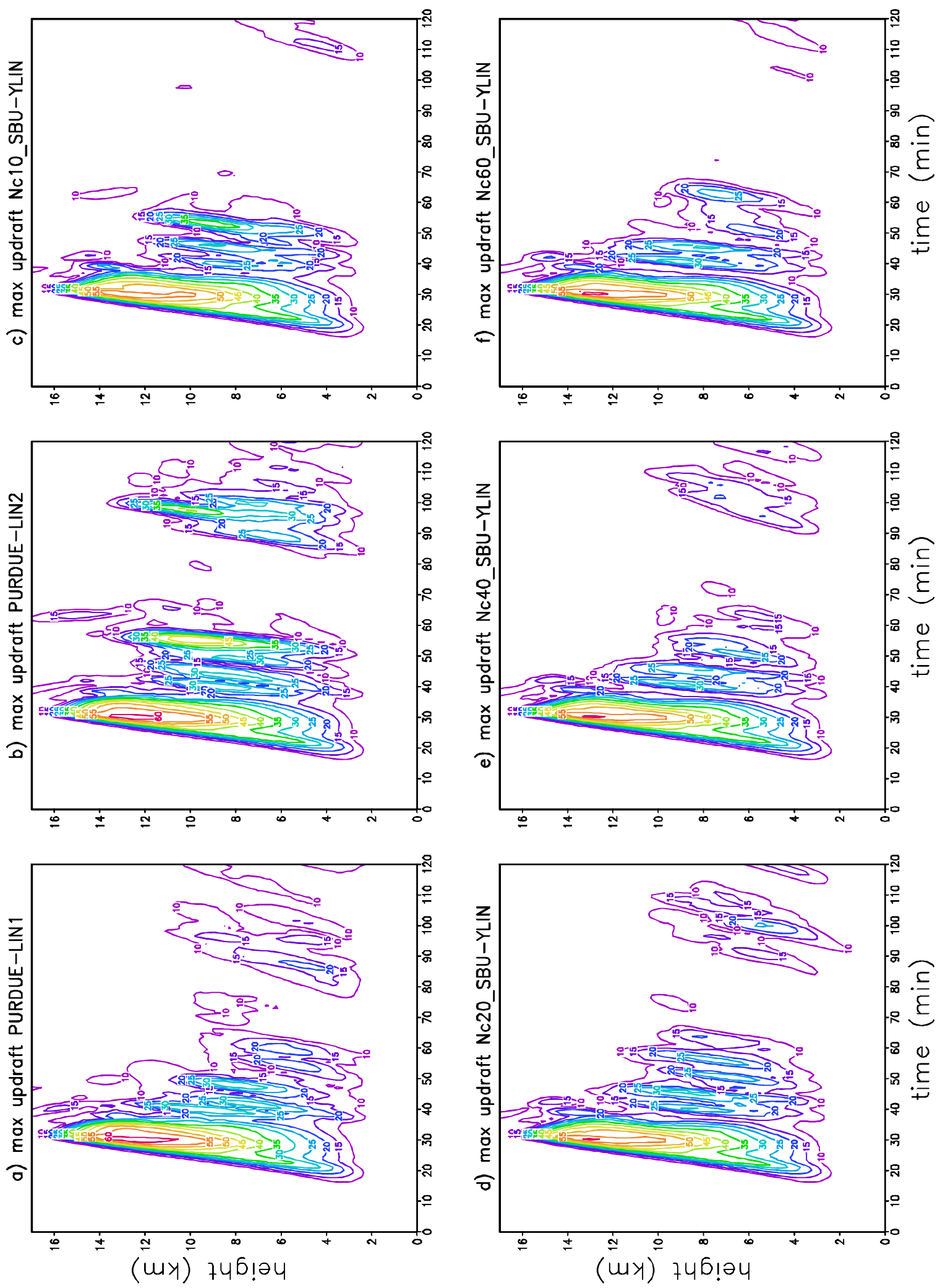

Fig. 1. Maximum Updraft $\left(\mathrm{ms}^{-1}\right)$ for the a) PURDUE-LIN1, b) PURDUE-LIN2, SBU-YLIN simulations with $\mathrm{Nc}=$ c) 10 , d) 20, e) 40 and f) 60 . 

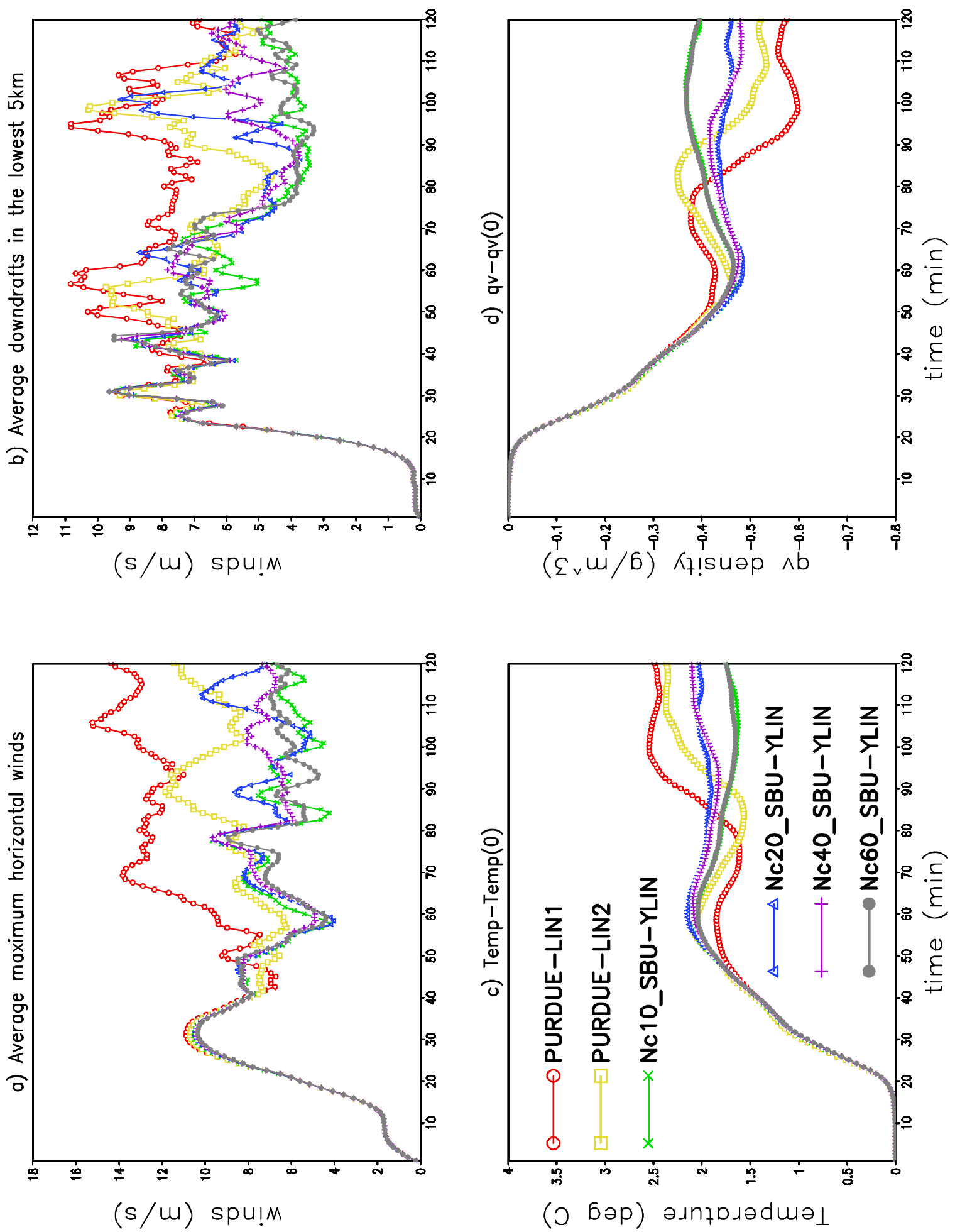

Fig. 2. Domain average a) maximum surface winds,b) maximum downdrafts in the lowest $6 \mathrm{~km}$ of the atmosphere, c) temperature change relative to the initial conditions and d) water vapour change relative to the initial conditions for the PURDUE-LIN1, PURDUE-LIN2, SBU-YLIN simulations with Nc= $10,20,40$ and 60. 


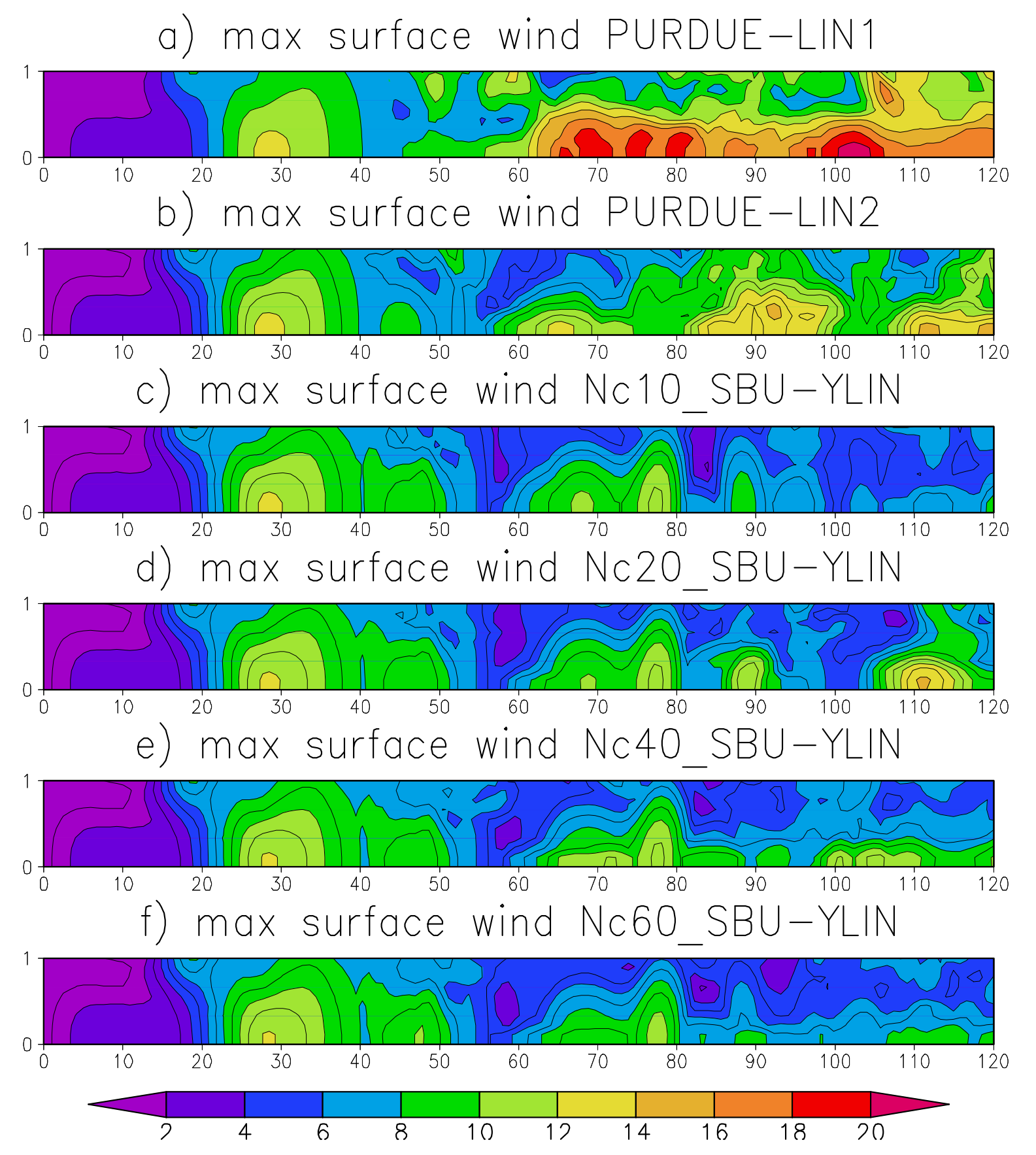

Fig. 3. The maximum absolute horizontal wind $\left(\mathrm{ms}^{-1}\right)$ in the first $1 \mathrm{~km}$ of the atmosphere for a) PURDUE-LIN1, b) PURDUE-LIN2, SBU-YLIN simulations with Nc=c) 10, d) 20, e) 40 and f) 60.

over the first 40 minutes of all the simulations. The updrafts associated with the second cell are bigger in the PURDUE-LIN2 simulation compared to the PURDUE-LIN1, Nc20-SBUYLIN and Nc40-SBU-YLIN simulations. The differences beyond 40 minutes are due to the 
varying hydrometeor attributes simulated by the different schemes (see hydrometeor discussion below), which affect the cloud dynamics (i.e. downdrafts and the cold pool).

\section{b. Cold pool}

The maximum absolute values of the horizontal winds in the first $1 \mathrm{~km}$ of the atmosphere are similar for all six simulations in the first 40 minutes of the simulation (Fig 2a). Beyond 50 minutes PURDUE-LIN1 (Fig 3a) simulates the strongest surface winds, while the winds simulated by the SBU-YLIN configurations are the smallest. The cell redevelopment simulated by the PURDUE-LIN schemes seems to be the direct result of the cold pool, which is able to trigger a new cell through the uplift of warmer environmental air. The updrafts (Fig 1) in the second cell are bigger in the PURDUE-LIN2 simulation, even though the cold pool is stronger in the PURDUELIN1 simulation. The differences in the cold pools simulated by the SBU-YLIN configurations are small, however only two of the four configurations simulate redevelopment. The maximum surface winds along the surface are slightly stronger and deeper in the Nc20_SBU-YLIN (Fig 2a; 3d) and Nc40_SBU-YLIN (Fig 2a; 3e) configurations, between 80 and 90 minutes just before secondary redevelopment. Although the two configurations are only slightly stronger, they are able to trigger a second cell that the other two configurations are not able to simulate (Fig $3 \mathrm{c}$ and $3 \mathrm{f}$ ).

\section{c. Downdrafts}

The downdrafts in the simulations (Fig 2b) develop in response to the updrafts to complete the pressure perturbation field (observational studies have shown that on each side of a convective updraft is a downdraft that is forced by the downward pressure perturbation force found on either side of a buoyant element (Houze, 1993)). The downdrafts are additionally strengthened by precipitation drag and microphysics processes that absorb latent heat. The downdrafts in the lowest $5 \mathrm{~km}$ of the atmosphere are generally bigger in the PURDUE-LIN1 simulation after 40 minutes, in comparison to all the other simulations 
performed. The PURDUE-LIN2 configuration generally simulates the second strongest downdrafts. These results are consistent with the magnitudes of the cold pool, with PURDUE-LIN1 simulating the highest surface wind magnitude, followed by PURDUELIN2. The SBU-YLIN configurations simulated downdrafts that are less variable relative to one another, compared to the PURDUE-LIN configurations. Between 70 and 80 minutes, two configurations (i.e. Nc20_SBU-YLIN and Nc40_SBU-YLIN) simulate slightly bigger downdrafts than Nc10_SBU-YLIN and Nc60_SBU-YLIN (Table 1). These results are also consistent with the cold pool simulations- the strongest downdrafts are associated with the strongest cold pools which are in turn associated with secondary cell redevelopment.

\section{d. Temperature and water vapour}

The area-averaged temperature over the simulation domain (Fig. 2c) starts to increase in all the simulations as soon as water vapour (Fig. 2d) starts decreasing in the model, to form hydrometeors in the liquid and ice stages (latent heat is released during these phase conversions). In all the simulations, between 60 and 80 minutes, there is a decrease in temperature, which indicates latent heat absorption and an increase in water vapour. The 60 to 80 minutes corresponds to a time when the updrafts were at a minimum in all the simulations (Fig. 1) and hence an increase in water vapour is an indication of a lack of supply of moist air by updrafts. The updrafts continued to be at a minimum for the SBU-YLIN configurations that did not simulate redevelopment. By the end of the simulation, PURDUELIN1 has warmed up the most, followed by the PURDUE-LIN2, and then the Nc20_SBUYLIN and Nc40_SBU-YLIN simulations (Table 1). The two SBU-YLIN scheme configurations that do not simulate redevelopment, warm up the least. The amount of water vapour converted to hydrometeors corresponds to the amount of heating in the atmosphere. The simulation with the least amount of heating, converted the least amount of water vapour to hydrometeors. 
Figure 4 shows the change in temperature over a two hour period with height, relative to the initial conditions. There is an increase in temperature throughout the atmosphere as hydrometeors start forming because of latent heat release. The biggest increase in temperature is between 6 and $10 \mathrm{~km}$ above the surface. From about 45 minutes the temperature is lower along the surface compared to the initial state. The surface temperature is the lowest in the PURDUE-LIN1 simulation, which also exhibits the strongest cold pool. PURDUE-LIN2 simulates the second lowest temperature and the second strongest cold pool. There are small differences in the SBU-YLIN temperature simulations, as was also noted in the surface winds simulations, especially along the surface. The simulations that exhibit redevelopment (i.e. PURDUE-LIN1, PURDUE-LIN2, Nc20_SBU-YLIN and Nc40_SBUYLIN) warm up the most at a height of about $8 \mathrm{~km}$ above sea level towards the end of the simulation. This result is because of more latent heat release as more hydrometeors form due to updrafts associated with the secondary cell redevelopment, which shows that there is a feedback mechanism between the microphysics processes and the dynamics.

The average temperature in the PURDUE-LIN1 scheme is higher than in the PURDUE-LIN2 scheme simulations, at a height where updrafts associated with the second cell occur (Figure 5). This result can explain a possible mechanism for the updrafts associated with the PURDUE-LIN2 scheme being bigger than those associated with PURDUE-LIN1 even though the cold pool is stronger in the latter. When the environmental temperature is higher, the difference in temperature between the environment and thermals will be smaller, and hence the updrafts will also be smaller.

The temperature differences in the SBU-YLIN configurations are small. Previous studies have shown that by decreasing the size of cloud droplets and increasing their 

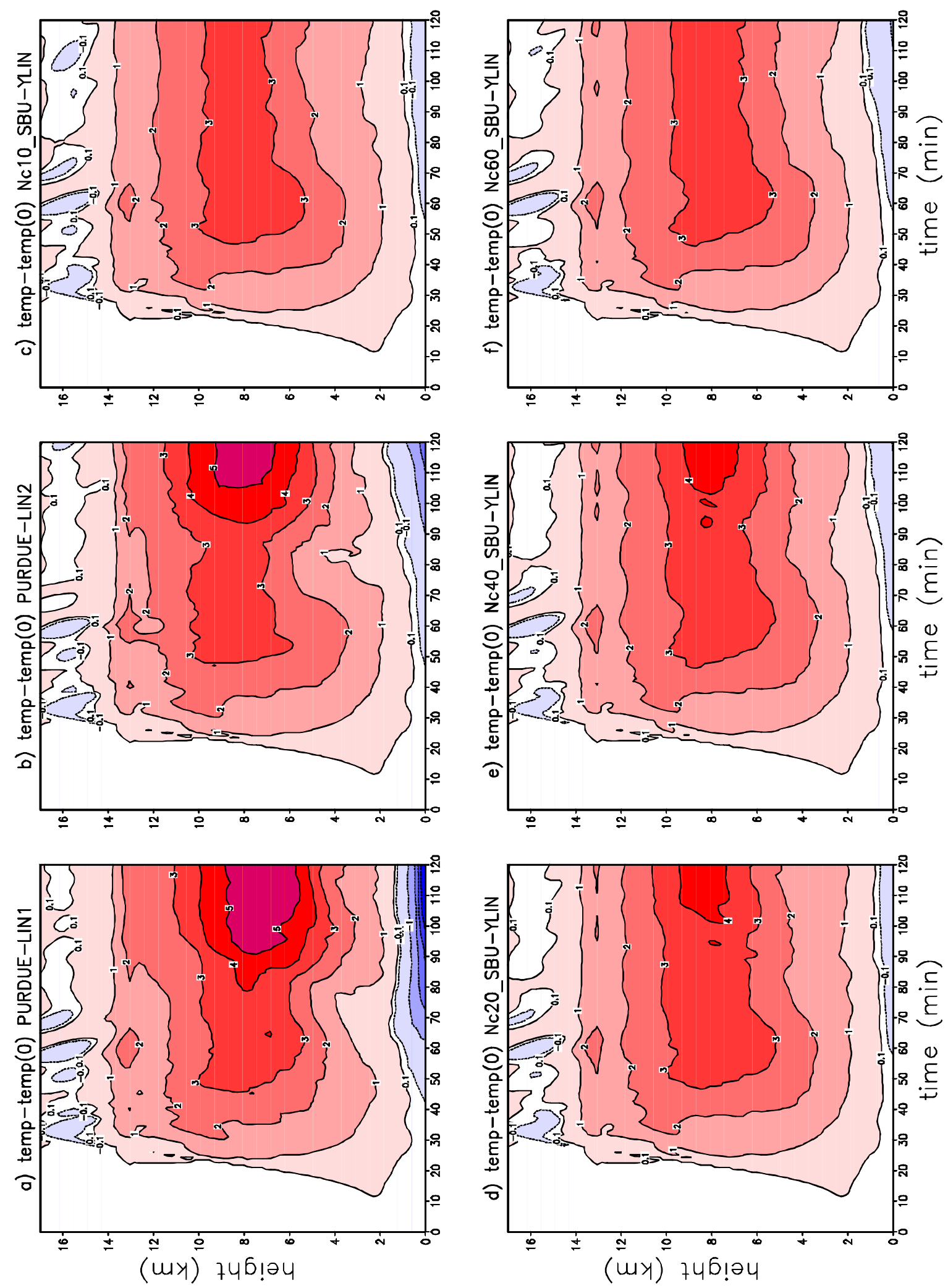

Fig. 4. The temperature change $\left({ }^{0} \mathrm{C}\right)$ with height for a) PURDUE-LIN1, b) PURDUE-LIN2, SBUYLIN simulations with $\mathrm{Nc}=$ c) 10 , d) 20 , e) 40 and f) 60 .over a two hour period.. 


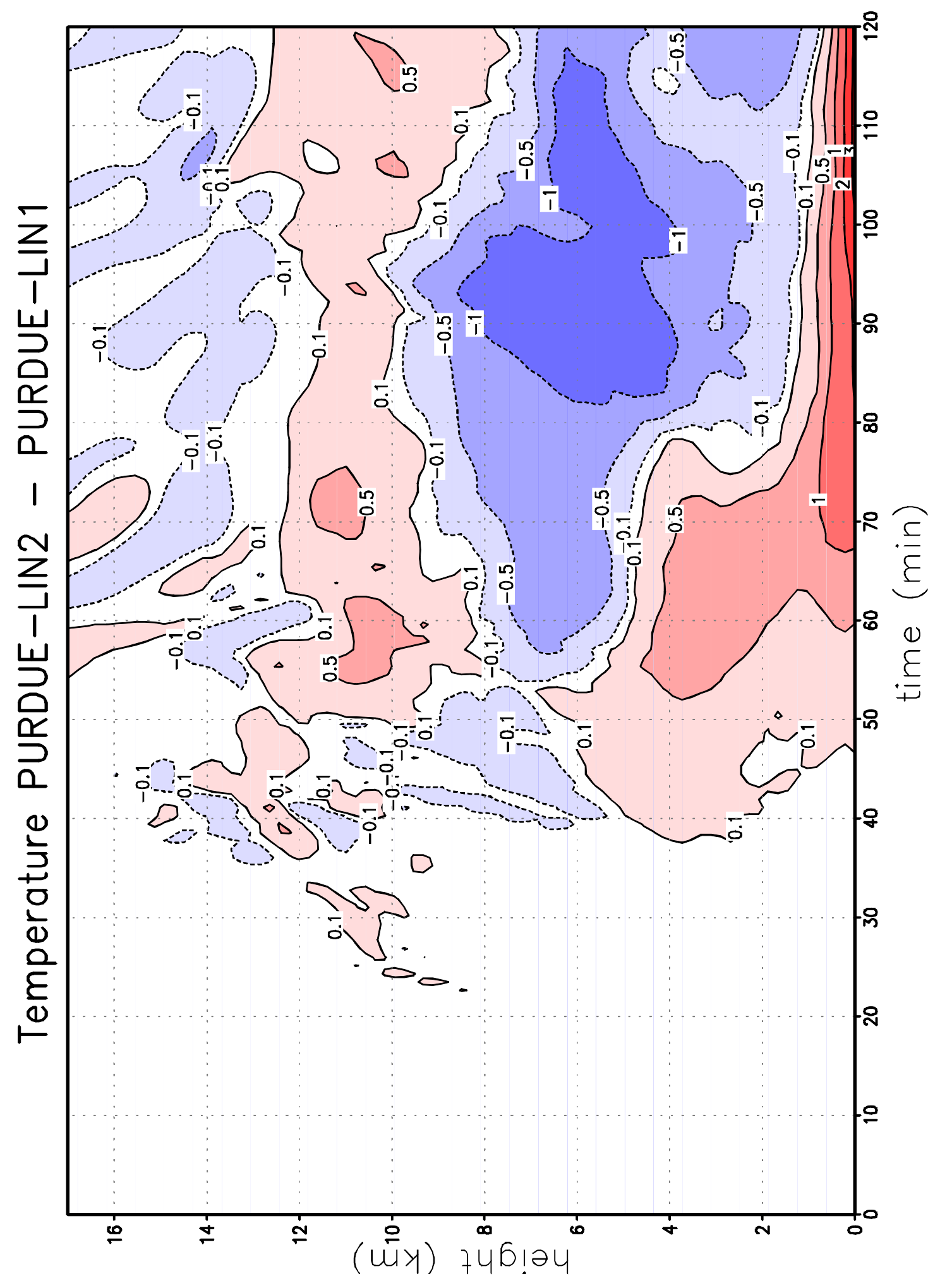

Fig. 5. Temperature $\left({ }^{0} \mathrm{C}\right)$ with height for PURDUE-LIN1 simulation minus PURDUE-LIN2 simulation. 

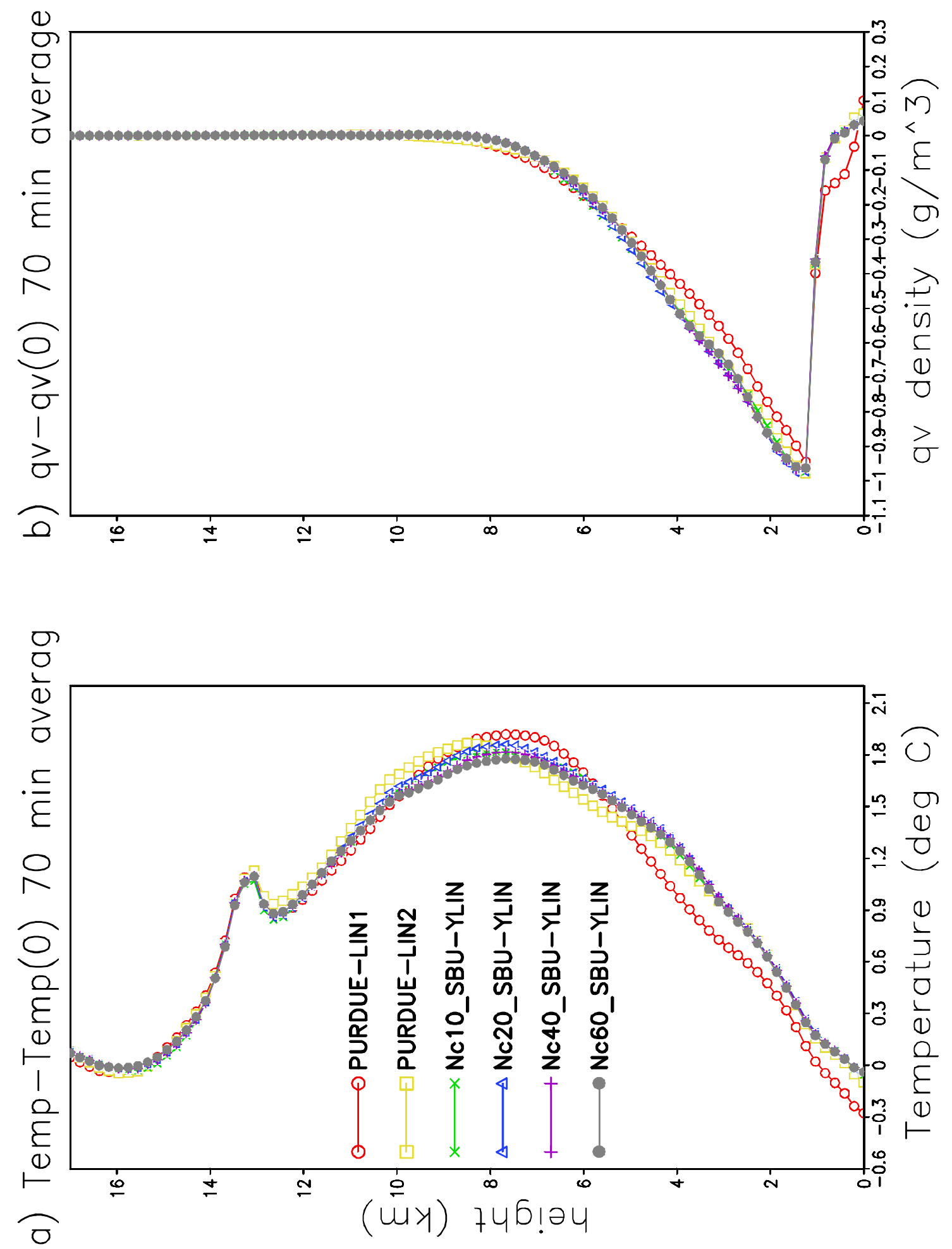

Fig. 6 . The first 70 minute average a) temperature change relative to the initial conditions and b) water vapour change relative to the initial conditions for the PURDUE-LIN1, PURDUE-LIN2, SBU-YLIN simulations with $\mathrm{Nc}=10,20,40$ and 60 with height 
concentration, precipitation efficiency is reduced. The cold pool associated with continental storms (i.e. those with smaller droplets due to increased aerosol concentration) were found to be stronger than those associated with maritime storms because of increased evaporation of smaller droplets. The differences in the cloud droplet distribution in the SBU-YLIN conducted in this study results in much smaller differences along the surface compared to other studies. This is also confirmed by the average temperature lines with height (Figure 6a) which shows all the lines associated with SBU-YLIN falling on top of one another along the surface. Despite the temperature anomalies looking very similar at the surface, two of the configurations simulate a cold pool that is able to trigger secondary redevelopment. This result appears to be related to nonlinearities in the model, because there is no clear direction in which we can say redevelopment is taking place. Nc10_SBU-YLIN has the largest cloud droplets, while Nc60_SBU-YLIN has the smallest cloud droplets and both of these

configurations do not simulate redevelopment. Nc20_SBU-YLIN and Nc40_SBU-YLIN have cloud droplet sizes that are between Nc10_SBU-YLIN and Nc60_SBU-YLIN.

\section{e. Hydrometeors}

PURDUE-LIN1 (Fig 7a; 8a) simulates the most rainfall, followed by PURDUE-LIN2 (Fig 7b;8b) and then by Nc40_SBU-YLIN (Fig 7e; 8e). In the PURDUE-LIN simulations, the first cell is associated with more cloud and precipitating ice, while the second cell towards the end of the simulation is associated with more cloud water. This result is because the updrafts associated with the first cell are stronger and therefore able to transport moisture to the high altitude cold regions where more ice forms. The updrafts in the second cell are weaker and shallower and therefore their impact is felt more in the lower troposphere, where more cloud water forms. The first cell is associated with more cloud ice in the SBU-YLIN configurations as well. 

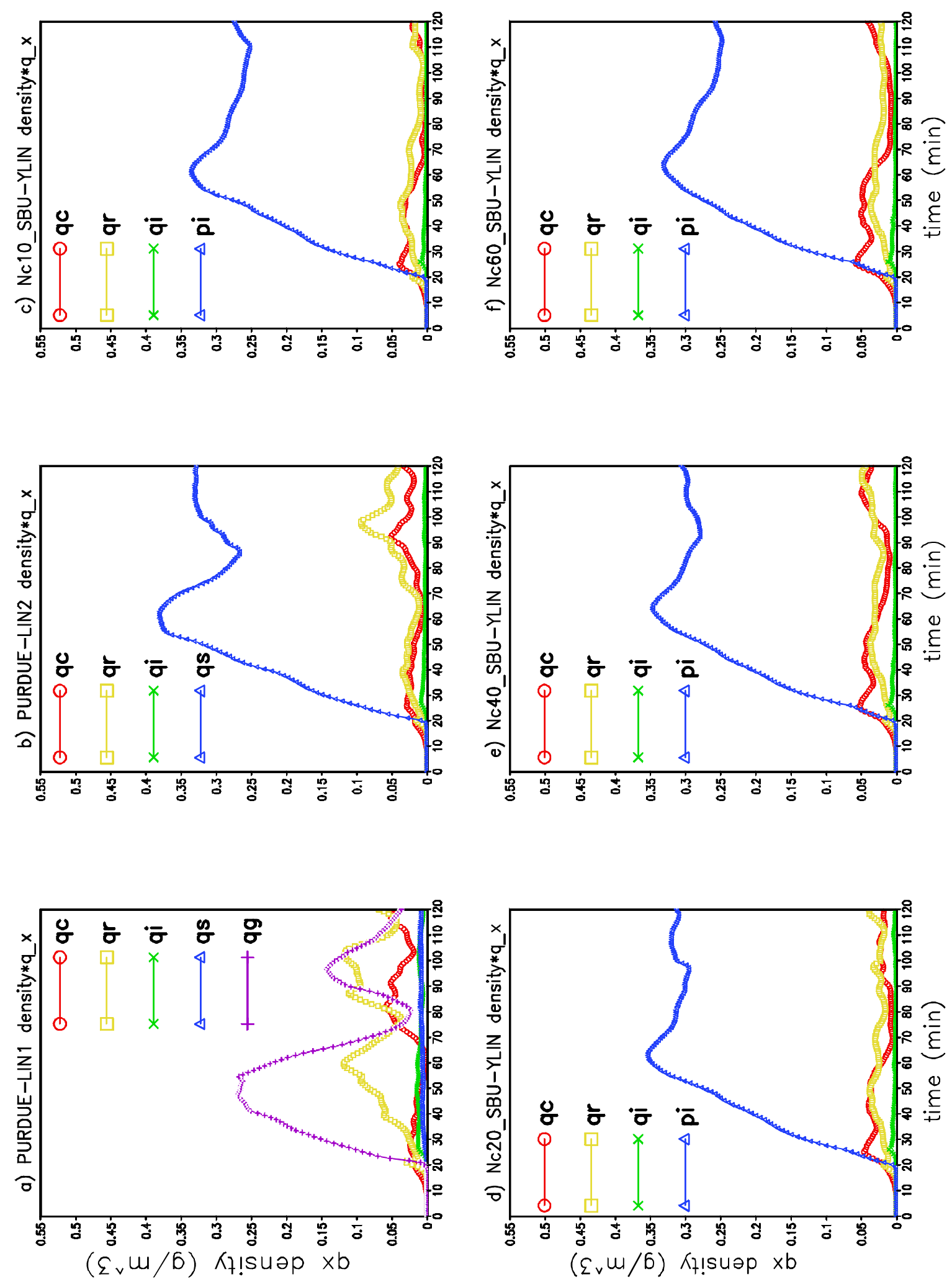

Fig. 7. The mixing ratios of all hydrometeors with time for a) PURDUE-LIN1, b) PURDUE-LIN2, SBU-YLIN simulations with $\mathrm{Nc}=\mathrm{c}$ ) 10 , d) 20, e) 40 and f) 60 . 

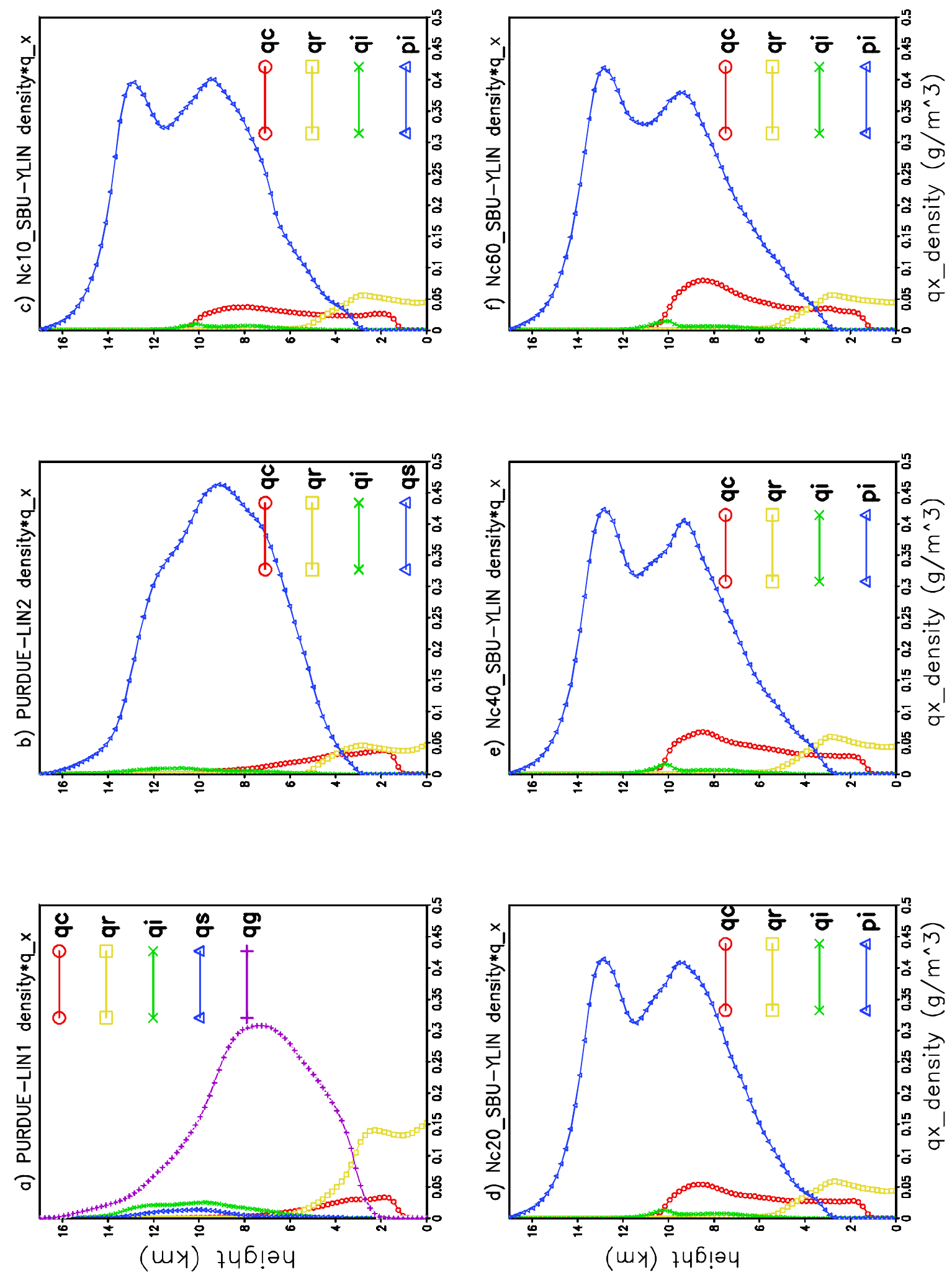

Fig. 8. The mixing ratios of all hydrometeors with height for a) PURDUE-LIN1, b) PURDUE-LIN2, SBU-YLIN simulations with $\mathrm{Nc}=$ c) 10 , d) 20, e) 40 and f) 60 made in the first 70 minutes of the simulation. 
The simulated cloud water by the SBU-YLIN microphysics scheme associated with the first cell is more than in the simulations employing the PURDUE-LIN schemes (Fig. $7 ; 8$ ). Fig 8 shows the different hydrometeors with height averaged over the first 70 minutes of simulation. The cloud droplets are smaller with an increasing number of $\mathrm{N}_{\mathrm{OC}}$, and the smaller the droplets the lighter they are and can be advected to the upper parts. Nc60_SBU-YLIN has the most droplets between 8 and $10 \mathrm{~km}$ because it has the smallest cloud droplets. The effect of the different cloud droplet distribution is more visible between 5 and $10 \mathrm{~km}$ but it is much smaller closer to the surface as evidenced in the temperature anomaly vertical profile (Fig. 6a). Nc60_SBU-YLIN simulates the lowest temperature because of increased evaporation as a result of smaller droplets in that region, however as already mentioned these differences do not reach the surface.

Rainfall has two maxima, the first between 60 and 70 minutes, and the second after 100 minutes, in the PURDUE-LIN1 simulation (Fig. 7a). The PURDUE-LIN2 simulation (Fig. 7b) simulates less rainfall than PURDUE-LIN1, which is in agreement with the findings of Hong and Lim (2006), who compared a six class microphysics scheme with its five class predecessor and found that the amount of rainfall increased and its peak intensity became stronger with more hydrometeors. The SBU-YLIN scheme simulates the least amount of rainfall with all its configurations (Fig. 7c-f; 8c-f).

The amount of rainfall simulated by each scheme is proportional to the magnitude of the maximum horizontal wind in the lower levels and associated cold pool. In all the simulations precipitating ice does not reach the surface, but is converted to other hydrometeors (Fig. 7) and water vapour (Fig. 2d; 6b). The dominating hydrometeor is the largest ice in all the simulations; graupel in PURDUE-LIN1 (Fig. 7a), snow in PURDUELIN2 (Fig. 7b) and precipitating ice (snow and graupel) in SBU-YLIN configurations (Fig. 7c-f). In the PURDUE-LIN1 simulation, graupel reaches maximum concentrations after 
about 40 minutes and subsequently starts decreasing. The decrease in graupel concentration is directly related to the occurrence of the first rainfall peak, and occurs in conjunction with a slight increase in water vapour and a slight decrease in temperature. The temperature decrease (Fig. 2c) is the result of latent heat absorption associated with melting and evaporation. Graupel reaches a minimum after about 75 minutes of simulation and starts to increase again after 80 minutes in relation to the second cell's updrafts. A peak is reached just before 100 minutes, coinciding with the second rainfall peak, and then graupel decreases to a minimum at about 2 hours.

These results suggest the heavier graupel particles fall faster and melt below freezing level to form rainfall. The rain water droplets that form in this way are big enough to reach the surface before evaporating. The melting graupel particles reduce the temperature and strengthen the downdraft that eventually acts to cut the supply of moist air to the storm. The downdraft forms a cold pool that acts as a trigger for a second cell. Rainfall at the surface is usually preceded by a downdraft reaching the surface, and a rainfall maximum occurs in the PURDUE-LIN1 simulation just before a minimum in other hydrometeors is reached.

The amount of snow simulated by the PURDUE-LIN2 scheme (Fig 7b) is greater than the amount of graupel produced in the PURDUE-LIN1 simulation (Fig. 7a). Snow starts decreasing after about 60 minutes, but unlike the graupel in the PURDUE-LIN1 simulation it does not decrease to almost zero. A local minimum is reached after 80 minutes, where after the amount of snow starts to increase again because of the second cell's updrafts. As snow decreases in the PURDUE-LIN2 simulation, the water vapour increases and temperature decreases slightly, which shows that there was cooling due to latent heat absorption. The decrease in snow concentrations is related to a slight increase in the amount of rainfall, but not nearly as in the case of decreasing graupel concentrations in the PURDUE-LIN1 
simulation. The decrease in snow commences later in the simulation than in the case of decreasing in graupel.

The behaviour of precipitating ice (snow + graupel) in the SBU-YLIN simulation (Fig. 7c-f) follows that of snow in the PURDUE-LIN2 run (Fig. 7b). The amount of precipitating ice is about the same as of snow in the PURDUE-LIN2 run, both of which are higher than graupel in the PURDUE-LIN1 simulation. The peak in precipitating ice occurs almost at the same time as the peak in snow in the PURDUE-LIN2 run, and later than the peak in graupel in the PURDUE-LIN1 simulation. With the decrease in precipitating ice, water vapour increases slightly. There are small differences in the simulated hydrometeors by SBU-YLIN configurations (Figure 7c-f, Fig 8c-f) that eventually determine the occurrence or nonoccurrence of the second cell. In the simulations with redevelopment, the second cell leads to an increase in the amount of hydrometeors.

\section{Summary and Conclusion}

Two microphysics schemes (i.e. PURDUE-LIN (Chen and Sun, 2002) and SBUYLIN (Lin and Colle, 2011)) were applied in the NSM to perform two-dimensional thunderstorm simulations. The experimental design followed that of Weisman and Klemp (1982), where a thunderstorm is initiated by introducing a warm thermal in an environment with a prescribed thermodynamic profile. The simulations were performed for an integration period of two hours, without environmental wind shear. The PURDUE-LIN BMS was used both as a five-class (i.e. excluding graupel) (PURDUE-LIN2) and a six-class (i.e. with graupel) (PURDUE-LIN1) scheme. SBU-YLIN was used with four configurations where different intercepts of cloud water with values $10,20,40$ and $60 \times 10^{6} \mathrm{~m}^{-4}$ were used. Increasing the value of the intercept results in a cloud droplet distribution with more small droplets. At the beginning of the simulation only water vapour was provided to the model, and hydrometeors were allowed to form freely in accordance to the microphysics processes in 
the BMSs. A horizontal resolution of $500 \mathrm{~m}$ was used, and the vertical resolution was kept constant at an average of $200 \mathrm{~m}$ in all the simulations.

The PURDUE-LIN1 scheme simulated more rainfall than PURDUE-LIN2, indicating that graupel is a potent hydrometeor in inducing precipitation. Hong and Lim (2006) consistently found that when comparing a six-class microphysics scheme with its five-class predecessor, the six-class scheme generally simulates more rainfall. Towards the end of the two hour integration period, a second cell develops in both PURDUE-LIN runs, but it is stronger in the PURDUE-LIN2 simulation. The second cell is triggered by the outflow and cold pool that forms when downdrafts from the first storm reach the surface. The temperature deviations at the surface are higher in the PURDUE-LIN1 (including graupel) configuration, which corresponds to the cold pool being more intense in this simulation. This results from the melting of graupel particles, which form relatively large raindrops and decrease the temperature trough latent heat absorption, thereby strengthen the downdrafts, which in turn result in a more intense cold pool. Although the cold pool is generally more intense in the PURDUE-LIN1 simulations, the updraft of the second storm is generally stronger in the PURDUE-LIN2 simulations. The temperature is higher at the heights where updrafts form in the PURDUE-LIN1 simulations, implying a more stable environment, resulting in comparatively smaller updrafts.

Redevelopment is simulated for only two of the four SBU-YLIN simulations (Table 1). The downdrafts and the surface winds are slightly stronger in the SBU-YLIN configurations that do simulate the second cell, compared to those that do not exhibit redevelopment, but the differences are relatively small. Of the two SBU-YLIN configurations that do not simulate redevelopment, one uses the largest cloud droplets, while the other uses the smallest cloud droplets, and the two configurations that simulate redevelopment have cloud droplet sizes in the middle of the two that do not simulate redevelopment. This result 
shows that small differences in the downdrafts and cold pool intensities, which lead to redevelopment or no redevelopment, may be related to nonlinearities in the model. The configurations that simulated the second cell loose the most water vapour and warm up the most.

Previous studies have shown that the dynamics of the storms are influenced by the size distribution of liquid droplets and ice particles in a microphysics scheme. Our study further confirms this, and additionally suggests that small differences in hydrometeors can determine whether or not there is cell redevelopment - due to the nonlinear nature of the relevant atmospheric processes. The redevelopment in turn influences the amount of hydrometeors simulated to be present by each scheme by the end of the simulation period. Our results also show that the use of different schemes result in bigger differences, while using one scheme with different configurations results in smaller differences, regarding the simulated dynamics and hydrometeors. Small differences in the simulation of hydrometeors can result in changes in the dynamics of the storm, emphasizing the nonlinearity of the system. The results suggest that the stochastic treatment of microphysics can be used to describe the uncertainty envelope associated with storm development and redevelopment. Insights into the causes of differences in the simulation of this individual thunderstorm may assist with understanding the differences in simulations of ensembles of clouds over larger domains. Qualitatively, the simulations provide insight into the interplay between cloud microphysics and cloud dynamics, and points out the potential for better describing the uncertainty range associated with projections of future climate change, through the improvement and stochastic application of cloud microphysics schemes.

Acknowledgements: The authors would like to acknowledge the CSIR Natural Resources and the Environment for funding this work through parliamentary grant funding and Young 
Researcher Establishment Funds (provided to the first author). The Centre for High Performance Computing (CHPC) in South Africa is acknowledged for supporting the study in its initial stages. The Applied Centre for Climate and Earth System Science (ACCESS) is acknowledged for additional funding to support the atmospheric model development research described in the paper. The two anonymous reviewers are also acknowledged for their comments, which helped to improve the paper.

\section{References}

Arakawa A, 2004: Review article: The Cumulus parameterisation Problem: Past, Present and Future. J. Clim., 17, 2493-252.

Abiodun BJ, JM Prusa and WJ Gutowski Jr, 2008a: Implementation of a nonhydrostatic, adaptation, adaptive-grid dynamics core in CAM3. Part I: Comparison of dynamics cores in aqua-planet simulations. Climate Dyn. 31,795-810.

Chen S and W Sun, 2002: A One-dimensional Time Dependent Cloud Model. J. Meteo. Soc. Japan, 80, 99-118.

Colle BA and CF Mass, 2000: The 5-9 February 1996 Flooding Event over the Pacific Northwest: Sensitivity Studies and Evaluation of the MM5 Precipitation Forecast. Mon. Wea. Rev., 128, 593-617.

Ćurić M, D Jane and V Vučković, 2007: Cloud seeding impact on precipitation as revealed by cloud-resolving mesoscale model. Meteorol. Atmos. Phys., 95, 179-193.

Davies T, A Staniforth, N Wood and J Thuburn, 2003: Validity of anelastic and other equation sets inferred from normal-mode analysis. Quart. J. Roy. Meteor. Soc., 129, $2761-2775$. 
Davies T, MJP Cullen, AJ Malcolm, MH Mawson, A Staniforth, AA White and N Wood, 2005: A new dynamical core for the Met Office's global and regional modelling of the atmosphere. Quart. J. Roy. Meteor. Soc., 131, 1759-1782.

Dawson II DT, M Xue, JA Milbrandt and MK Yau, 2010: Comparison of Evaporation and Cold Pool Development between Single- Moment and Multimoment Bulk Microphysics Schemes in Idealized Simulations of Tornadic Thunderstorms. Mon. Wea. Rev., 138, 1152-1171.

Durran DR, 1999: Numerical Methods for Wave Equations in Geophysical Fluid Dynamics. Springer, 465pp.

Engelbrecht FA, 2006: Theory and application of quasi-elastic equations in terrain-following coordinates based on the full pressure field. Doctoral thesis. University of Pretoria. Published online. 208 pp.

Engelbrecht FA, JL McGregor and CJdeW Rautenbach, 2007: On the development of a new nonhydrostatic atmospheric model in South Africa. S. Afr. J. Sci., 103, 127-134.

Gao S, L Ran and X Li, 2006: Impacts of Ice Microphysics on Rainfall and Thermodynamic Processes in the Tropical Deep Convective Regime: A 2D Cloud-Resolving Model Study. Mon. Wea. Rev., 134, 3015-3024.

Gilmore MS, JM Straka and EN Rasmussen, 2004: Precipitation Uncertainty Due to Variations in Precipitation particle parameters within a Simple Microphysics Scheme. Mon. Wea. Rev., 132, 2610-2627.

Grabowski WW, 2000: Coupling Cloud Processes with the Large-scale Dynamics Using the Cloud-Resolving Convection Paramaterization (CRCP). J. Atmos. Sci.,58, 978-997.

Grubišić V, RK Vellore and AW Huggins, 2005: Quantitative Precipitation Forecasting of Wintertime Storms in the Sierra Nevada: Sensitivity to the Microphysical Parameterization and Horizontal Resolution. Mon. Wea. Rev., 133, 2834-2859. 
Harper K, LW Uccellini, E Kalnay, K Carey and L Morone, 2007: 50 ${ }^{\text {th }}$ Anniversary of Operational Numerical Weather Prediction. Bull. Amer. Meteor. Soc., 88, 639-650.

Houze Jr RA, 1993: Cloud Dynamics.Academic Press, 573pp.

Holtslag AAM and BA Boville, 1993: Local Versus Nonlocal Boundary-Layer Diffusion in a Global Climate Model. J. Clim., 6, 1825-1842.

Hong S and JJ Lim, 2006: The WRF Single-Moment 6-Class Microphysics Scheme (WSM6). J. Korean Meteor. Soc., 42, 129-151.

Kessler E, 1969: On the Distribution and Continuity of Water Substance in Atmospheric Circulations. Meteor. Monogr., Amer. Meteor. Soc., 84 pp.

Khain A and B Lynn, 2009: Simulation of a supercell storm in clean and dirty atmosphere using weather research and forecast model with spectral bin microphysics. Journal of Geophysical Research, 114, D19209, doi:10.1029/2009JD011827.

Khain A, D Rosenfeld and A Pokrovsky, 2005: Aerosol impact on the dynamics and microphysics of deep convective clouds. Quart. J. Roy. Meteor. Soc.131, 2639-2663.

Khairoutdinov M, D Randall, and C DeMott, 2004: Simulations of the Atmospheric General Circulation Using a Cloud-Resolving Model as a Superparameterization of Physical Processes. J. Atmos. Sci., 62, 2136-2154.

Lin Y and BA Colle, 2011: A New Bulk Microphysical Scheme That Includes Riming Intensity and Temperature-Dependent Ice Characteristics. Mon. Wea. Rev., 135, 10131035.

Lin Y, RD Farley and HD Orville, 1983: Bulk Parametrization of the Snow Field in a Cloud Model. J. Climate App. Meteor., 22, 1065-1090.

Liu C and MW Moncrief, 2007: Sensitivity of Cloud-Resolving Simulations of Warm-Season Convection to Cloud Microphysics parameterisations. Mon. Wea. Rev., 135, 28542868. 
Liu L and PH Daum, 2004: parameterization of the Autoconversion Process. Part I: Analytical Formulation of the Kessler-Type Parameterizations. J. Atmos. Sci., 61, 1539-1548.

Louis J-F, 1979: A Parametric Model of Vertical Eddy Fluxes in the Atmosphere. Bound.Layer Meteor., 17, 187-202.

Miller MJ, 1974: On the use of pressure as vertical co-ordinate in modelling convection. Quart. J. Roy. Meteor. Soc., 100, 155-162.

Miller MJ and RP Pearce, 1974: A three dimensional primitive equation model of cumulonimbus convection. Quart. J. Roy. Meteor. Soc., 100, 133-154.

Miller MJ and AA White, 1984: On the non-hydrostatic equation in pressure and sigma coordinates. Quart. J. Roy. Meteor. Soc., 110, 515-533.

Morrison H, G Thompson, and V Tatarskii, 2009: Impact of cloud microphysics on the development of trailing stratiform precipitation in a simulated squall line: Comparison of one- and two-moment schemes. Mon. Wea. Rev., 137, 991-1007.

Morrison $\mathrm{H}$ and $\mathrm{J}$ Milbrandt, 2011: Comparison of Two-Moment Bulk Microphysics Schemes in Idealised Supercell Thunderstorm Simulations. Mon. Wea. Rev., 139, 1103-1130.

Palmer TN, 2012: Towards the Probabilistic Earth-system simulator: a vision for the future of climate and weather prediction. Q.J.R. Metorol. Soc. DOI:10.1002/ qj.1923.

Phillips NA, 1956: A coordinate system having some special advantages for numerical forecasting. J Meteor., 14, 184-185.

Randall DA, K Xu, RJC Sommerville and S Iacobellis, 1996: Single-Column Models and Cloud Ensemble Models as Links between Observations and Climate Models. $J$. Climate, 9, 1683-1697. 
Randall D., M. Khairoutdinov, A. Arakawa, and W. Grabowski, 2003: Breaking the Cloud Parameterization Deadlock. Bull. Amer. Meteor. Soc., 84, 1547-1564.

Rutledge SA and PV Hobbs, 1983: The Mesoscale and Microscale Structure and Organization of Clouds and Precipitation in Midlatitude Cyclones. VII: A Model for the seeder-feeder process in warm-frontal rainbands. J. Atmos. Sci., 40, 1185-1206.

Rutledge and Hobbs, 1984: The mesoscale and microscale structure and organization of clouds and precipitation in midlatitude cyclones. XII: A diagnostic modeling study of precipitation development in narrow cold-frontal rainbands. J. Atmos. Sci., 41, 29492972.

Satoh M, H Tomita, H Miura, S Iga and T Nasuno, 2005: Development of a global cloud resolving model - a multi-scale structure of tropical convections. J. Earth Simulator, 3, 11-19.

Skamarock, W. C., J. B. Klemp, J. Dudhia, D. O. Gill, D. M. Barker, W. Wang, and J. G. Powers, 2005: A description of the Advanced Research WRF Version 2. NCAR Tech Notes $-468+\mathrm{S}$.

Stensrud, D. J., 2007: parameterisation Schemes: Keys to Understanding Numerical Weather Prediction Models. Cambridge University Press, 488 pp.

Straka JM and ER Mansell, 2005: A Bulk Microphysics parameterisation with Multiple Ice Precipitation Categories. J. of Appl. Meteor., 44, 445-466.

Straka JM, 2009: Cloud and Precipitation Microphysics. Principles and Parameterizations. Cambridge University Press, 392pp.

Tao W-K, J Simpson and M McCumber, 1989: Notes and Correspondence, An Ice-Water Saturation Adjustment. Mon. Wea. Rev., 117, 231-235.

Tao W-K, J Simpson, D Baker, S Braun, M-D Chou, B Ferrier, D Johnson, A Khain, S Lang, B Lynn, C-L Shie, D Starr, C-H Sui, Y Wang and P Wetzel, 2003: Microphysics, 
radiation and surface processes in the Goddard Cumulus Ensemble (GCE) model. Meteorol. Atmos. Phys., 82, 97-137.

Van den Heever S and WR Cotton, 2004: The Impact of the Hail Size on Simulated Supercell Storms. J. Atmos. Sci, 61, 1596-1609.

Van Weverberg K, NPM Van Lipzig and L Delobbe, 2011: The Impact of Size Distribution Assumptions in a Bulk One-moment Microphysics Scheme on Simulated Surface Precipitation and Storm Dynamics during a Low-Topped Supercell Case in Belgium. Mon. Wea. Rev., 139, 1131-1147.

Wang C and JS Chang, 1993: A three-dimensional Numerical Model of Cloud Dynamics, Microphysics and Chemistry. 1. Concepts and Formulation. J. Geophys. Res., 98, $14827-14844$.

Weisman ML and JB Klemp, 1982: The Dependence of Numerically Simulated Convective Storms on Vertical Wind Shear and Buoyancy. Mon. Wea. Rev., 110, 504-520.

White AA, 1989: An extended version of a nonhydrostatic, pressure coordinate model. Quart. J. Royal Meteor. Soc., 115, 1243-1251.

Xu K and coauthors, 2000: Cloud-Resolving Model Intercomparison with ARM Summer IOP Data, 2000, Tenth RM Science Team Meeting Processes, San Antonio, March 13-17 2000.

Xue M, KK Droegemeier and V Wong, 2000: The Advanced Regional Prediction (ARPS)- A multi-scale nonhydrostatic atmospheric simulation and prediction model. Part I: Model dynamics and verification. Meteor. Atmos. Phys., 75, 75161-75193 